\title{
Dependência sintática e processos morfofonêmicos
}

Maria Cecília Magalhães Mollica Universidade Federal do Rio de Janeiro

\section{Abstract}

This study deals with the Sândi phenomena as a motịvated and a variable rule. It focuses the relationship between the syntactic dimension and the morphophonological system of the Portuguese language. The data show that a strong syntactic dependence decreases the probability of loss of segments in the boundary of the words. 


\section{OBJETO E OBJETIVOS}

7 ocalizo $^{1}$ neste texto variações que ocorrem em fronteiras intervocabulares no que diz respeito à presença/ausência de 1 crase e haplologia. Classificados como fenômenos de Sândi, trato desses processos morfofonêmicos visando especialmente a relação com a dimensão sintática da língua. Vejam-se os exemplos a seguir: ${ }^{2}$

\section{Crase:}

a) Bom. Assim, dizer com(o) + eles são? Com(o) + Ele é, assim, em casa?

$$
\text { (Lei - 4) }
$$

b) Agora, sobr(e) + a minha familia, é aquilo que você vê. São oit(o) + irmãos, meu irmão, meu padrasto, certo? e minha espos(a) + e a minha sobrinha.

$$
\text { (Rob - 15) }
$$

Haplologia:

a) ...Gosta muito de se divertir, go(sta) + tomar cerveja dela. Cerveja ela toma bastante!...

$$
\text { (Lei - 4) }
$$

b) ...Aí, perguntaram se eu tinha dinheiro den(tro) + de casa, se tinha jóias e ela disse que não.

$$
\text { (Dor - 29) }
$$

Sem pretender esgotar a leitura de estudos sobre o assunto, pode-se afirmar que os fenômenos de junção sintagmática são tratados na bibliografia sob dois aspectos: sincrônico e diacrônico. 
Diacronicamente, crase e haplologia são classificadas como tipos de mudança fonética, no interior das palavras, constituindo a reunião de duas vogais iguais em hiato, geminadas (cf. Câmara Jr, 1960, 1979, 1980).

No caso de crase:

- sedere $>$ seer $>$ ser

- colore $>$ coor $>$ cor

No caso de haplologia:

- simplicíssimo > simplíssimo

- esplendidíssimo > esplendíssimo

Dentre os trabalhos sobre o assunto, destaque-se o de Silveira (1972) que trata os fenômenos de juntura, especialmente a crase, como contração em juntura externa: a vogal inicial de um vocábulo com a inicial do seguinte. Ele nos dá como exemplo a reunião da preposição a e o artigo feminino.

vou a a praia $>$ vou à praia

Williams (1975:121), ao tratar de Sândi, afirma:

O fonema inicial ou final de uma palavra freqüentemente se desenvolvia como se fora medial, por causa de justaposição da palavra precedente ou seguinte. Trata-se de um fenômeno comum em português arcaico e dialetal; mas, com a tendência à individualização da palavra na linguagem literária moderna, desapareceu consideravelmente, salvo entre palavras que mantêm forte relação sintática, onde pode falar-se em fonologia sintática, e.g., combinações de pronomes conjuntivos com verbos e de preposiçôes com artigos e pronomes. (p.121)

Sincronicamente, os fenômenos de juntura são estudados e considerados justamente nos intervalos entre vocábulos, em cadeias processadas da fala. Esse tipo de tratamento é encontrado em textos como os de Souza (1983), Perini (1984), Alkmim e Gomes (1982). Outros estudos recentes mais avançados, como o de Bisol (1993), analisam o fenômeno de Sândi sob a perspectiva de uma fonologia não linear. 
Segundo Crystal (1988), juntura é o mesmo que ligação. O autor nos fornece a seguinte definição:

Termo usado na Fonologia com referência a um tipo de transição entre sons, em que um som é introduzido no final de uma palavra dependendo da palavra seguinte. Trata-se de uma característica marcante do francês, por exemplo, onde ț final de c'est é pronunciado quando seguido de uma vogal. Em português, o fenômeno, também chamado ocasionalmente de juntura (...). (p. 158)

Perini também menciona o fato de que a velocidade da fala é condição básica para a queda de segmentos, proporcionando processos morfofonêmicos. No caso da haplologia, por outro lado, há também questões discursivas envolvidas, como o status do referente, afora razões de natureza propriamente fonológica.

Assim, tal como Souza e Williams, que se referem à implicação sintática envolvida na ocorrência de haplologia, a questão importante neste texto consiste exatamente em fornecer evidências em favor da interdependência íntima entre os níveis morfofonológico e sintático da língua.

\section{BASE DE DADOS, METODOLOGIA E VARIÁVEIS}

Foram coletadas fronteiras sintagmáticas de oito falantes, tomados aleatoriamente, metade de homens e metade de mulheres, de cada uma das faixas de idade da amostra global "Censo" (cf. Naro, 1986). De cada falante, foram observados dez minutos de fala, marcando-se cada fronteira intervocabular. Obteve-se um total em torno de 700 dados de fronteiras de palavras, com juntura (crase e haplologia) ou sem juntura.

Os princípios metodológicos basearam-se nos postulados da Teoria de Variação (cf. Labov, 1972). Foram analisados 12 grupos de fatores: 11 de natureza fonético-fonológica e um de natureza sintática. A variável que me interessa discutir à luz da hipótese proposta categoriza os dados segundo o grau hierárquico de que 
gozam nas estruturas sintagmáticas. Observem-se os exemplos respectivos para cada fator.

\section{GRAU DE HIERARQUIA SINTÁTICA DA FRONTEIRA}

- entre períodos

... tenho outro também que é "panac(a) + ". Isso é a linguagem do vocabulário carioca, não é?

$$
(\mathrm{Cla}-27)
$$

- entre orações dentro de um período

... mas deu defeit(o) + e ficou desse jeito, nós temos que descer para ir abrir a porta.

$$
\text { (Dor - 29) }
$$

- entre SN1/SV

... agora, sobre a minha famíli(a) + , é aquilo que você vê.

$$
\text { (Rob - 15) }
$$

- entre SV/SN2

... então eu posso dizer que fo(i) + igual a de todo mundo, a minha infância foi de ... igual a de todo mundo.

$$
\text { (Rob - 15) }
$$

- dentro de um sintagma

... tudo querendo ... querend(o) + ir atrás dela ...

$$
\text { (Lei - 4) }
$$

\section{RELAÇĀO ENTRE ESTRUTURAS SINTÁTICAS E PROCESSOS MORFOFONÊMICOS}

Como já disse anteriormente, embora tenha testado inúmeras variáveis, quero focalizar neste trabalho tão somente a importância dos níveis sintático e morfofonêmico. Sustento portanto a idéia de 
que a junção entre palavras se dá preferencialmente em fronteiras sintagmáticas hierarquicamente mais dependentes, pois estas estão mais intimamente ligadas sintaticamente. Vejam-se os resultados na tabela, que confirmam a hipótese.

GRAU DE HIERARQUIA SINTÁTICA DA FRONTEIRA CRASE E HAPLOLOGIA X 0

\begin{tabular}{|l|c|c|c|}
\hline VARIÁVEIS & APL & PERC & PESO RELATIVO \\
\hline dentro do sintagma & $216 / 302$ & $72 \%$ & .69 \\
entre V/SN2 & $82 / 108$ & $76 \%$ & .71 \\
entre SN1/SV & $32 / 62$ & $52 \%$ & .36 \\
entre orações & $53 / 108$ & $49 \%$ & .48 \\
entre periodos & $4 / 15$ & $27 \%$ & .24 \\
\hline
\end{tabular}

Esses quantitativos exibem evidências de que os mecanismos de junção entre vocábulos se dão proporcionalmente ao grau de hierarquia sintática da fronteira em questão. Assim, as fronteiras em que os constituintes mantêm entre si maior dependência sintática são as que mais favorecem a junção: é o caso dos intervalos entre elementos dentro de um constituinte e na relação $\mathrm{V} / \mathrm{SN} 2$, pois SN2 é parte de V. Por outro lado, os limites em que os elementos possuem maior independência sintagmática constituem condicionamentos não favoráveis à junção: é o caso de intervalos entre períodos, entre orações de um mesmo período e entre $\mathrm{SN} 1 / \mathrm{SV}$, dentro da mesma sentença.

Essa estreita relação aqui demonstrada reafirma-se inconteste através de mecanismos de pontuação na língua escrita. Em diversos trabalhos, mais especificamente em Mollica (1994), eu provei que marcas de pontuação incidem sobre fronteiras de constituintes, preservando-lhes sua identidade, sem que haja qualquer possibilidade de quebra na unidade sintagmática. Neste sentido, sinais como a vírgula ocorrem mais quanto maior a independência dos consti- 
tuintes; inversamente, não ocorrem quando a dependência sintagmática é tal que chega a ameaçar a coesão entre os constituintes.

Exatamente nos intervalos de maior grau de dependência sintagmática, a tendência a que crase e haplologia operem acentuase. Em tais fronteiras, a pausa, na fala, emerge menos ou praticamente nunca, razão por que, na escrita, os sinais de pontuação também não ocorrem.

\section{ALGUMAS CONSIDERAÇÕES}

Devo frisar que apresentei neste texto apenas uma fase do projeto que prevê a análise de fenômenos de junturas morfofonêmicas em geral, por isso não trabalhei com grande número de dados. Ressalto também que crase e haplologia foram tomadas, nesta fase, como um único fenômeno, pois ambos os processos implicam perda de segmento. Cabe salientar que a crase é mais freqüente que a haplologia e, provavelmente, sensível a contextos próprios e/ou diferentes daquela.

Ressalto, por fim, o efeito positivo da hipótese sintática sobre junções intervocabulares, reafirmando com outros autores a estreita relação entre o nível sintático e o nível morfofonêmico da língua, ao fornecer evidências de correlação estatística relevante entre os subsistemas mencionados.

\section{NOTAS}

1 Este texto constitui versão revista de um dos estudos apresentados ao $\mathrm{CNPq}$ como Relatório Final do Projeto Uso da Lingua na Comunicação, no ano de 1989.

${ }^{2}$ A notação usada para marcar crase e haplologia é a seguinte: " $O$ " - os parênteses indicam que o(s) segmento(s) não foi/foram realizado(s); "+" - o sinal de " + " indica que houve a crase ou a haplologia na fronteira entre os vocábulos, tendo ocorrido, portanto, um dos fenômenos de Sândi em estudo. Ao final de cada exemplo aparece entre parênteses a indicação do falante que produziu o enunciado, extraído da Amostra Censo (cf. Naro, 1986). As reticências "..." indicam ou interrupção no fluxo da fala ou limite inicial e final de onde foi extraído o exemplo, pressupondo-se a existência de um contexto maior na Amostra Censo. 


\section{REFERÊNCIAS BIBLIOGRÁFICAS}

ALKMIN, Mônica G. R. \& GOMES, Christina A. Dois fenômenos de supressão de segmentos em limite de palavras. In: Ensaios de Lingüistica 7, Faculdade de Letras da UFMG, BH, 1982.

BISOL, Leda. Sândi vocálico externo. In: ILARI, Rodolfo (ör). Gramática do Português Falado. vol II, Editora da UNICAMP, SP. 2a. ed., 1993.

DUBOIS, Jean e outros. Dicionário de Lingüistica. Rio de Janeiro, 1973.

CÂMARA Jr., Joaquim Mattoso. Dicionáxio de Filologia e Gramática. Rio de Janeiro, Vozes, 1960.

. Dicionário de Lingüistica e Gramática. Rio de Janeiro, 1979.

. Estrutura da língua portuguesa. Rio de Janeiro, 1980.

CRYSTAL, David. Dicionário de Lingüistica e Fonética. Jorge Zahar Editor, Rio de Janeiro, 1988.

LABOV, $\mathbf{w}$. Sociolinguistic patterns. Philadelphia, University of Pennsylvania Press, 1972.

MOLLICA, Maria Cecilia. Sintaxe e Pontuação no Português contemporâneo. Boletim da ABRALIN (15), 1994.

NARO, A. J. Subsídios Sociolingüisticos à Educação. Relatório Final UFRJ/FINEP, Rio de Janeiro, 1986, mimeo.

PERINI, Mário A. Nota sobre o uso das velocidades de enunciação na descrição de fenômenos. Ensaios de Lingüistica (11), Faculdade de Letras da UFMG, $\mathrm{BH}, 1984$.

SILVEIRA, Sousa da. Lições de Português. Livros de Portugal, Rio de Janeiro, 1972.

SOUZA, Tânia Conceição C. de. Das Mudanças Morfofonêmicas em português. Ensaios de Lingüistica (10), Faculdade de Letras da UFMG, BH, 1983.

WILLIAMS, Edwin B. Do Latim ao Português. Tempo Brasileiro, Rio de Janeiro, 3a. edição, 1975. 